\title{
Long QT Syndrome 8
}

National Cancer Institute

\section{Source}

National Cancer Institute. Long QT Syndrome 8. NCI Thesaurus. Code C142894.

An autosomal dominant condition caused by mutation(s) in the CACNA1C gene, encoding voltage-dependent L-type calcium channel subunit alpha-1C. It is characterized by a prolonged QT interval that may result in torsade de pointes, ventricular fibrillation and/or sudden cardiac death. 